\title{
Research Division
}

\section{Federal Reserve Bank of St. Louis \\ Working Paper Series}

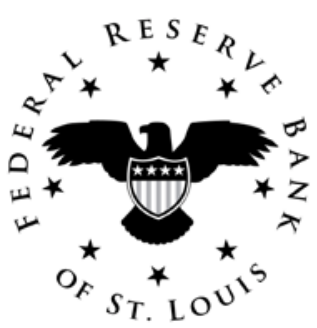

\author{
Export Market Diversification and Productivity \\ Improvements: Theory and Evidence From Argentinean Firms
}

\author{
Luciana Juvenal \\ And \\ Paulo Santos Monteiro
}

Working Paper 2013-015A

http://research.stlouisfed.org/wp/2013/2013-015.pdf

April 2013

\author{
FEDERAL RESERVE BANK OF ST. LOUIS \\ Research Division \\ P.O. Box 442 \\ St. Louis, MO 63166
}

\footnotetext{
The views expressed are those of the individual authors and do not necessarily reflect official positions of the Federal Reserve Bank of St. Louis, the Federal Reserve System, or the Board of Governors.

Federal Reserve Bank of St. Louis Working Papers are preliminary materials circulated to stimulate discussion and critical comment. References in publications to Federal Reserve Bank of St. Louis Working Papers (other than an acknowledgment that the writer has had access to unpublished material) should be cleared with the author or authors.
} 


\title{
Export Market Diversification and Productivity Improvements: Theory and Evidence From Argentinean Firms*
}

\author{
Luciana Juvenal $^{\dagger}$ \\ Federal Reserve Bank of St. Louis
Paulo Santos Monteiro $\ddagger$
University of York

April 11, 2013

\begin{abstract}
This paper examines the relationship between trade and investment in technology adoption when firms face demand uncertainty. Our model predicts that, for a given overall market size, exporting to several countries reduces firms' demand uncertainty and, hence, raises incentives to invest in productivity improvements. The effects of diversification are heterogeneous across firms: An additional foreign market matters more for firms exporting to fewer destinations. We test the proposed theory using a large sample of Argentinean manufacturing exporters. The predictions of the model find strong support in the data.
\end{abstract}

Keywords: Trade, Diversification, Technology Adoption

JEL Classification: F10, F14, D21

${ }^{*}$ We are grateful to seminar participants at the Federal Reserve Bank of St. Louis, the University of York and the Royal Economic Society Conference 2013 for useful suggestions. We thank Brett Fawley for outstanding research assistance. The views expressed are those of the authors and do not necessarily reflect official positions of the Federal Reserve Bank of St. Louis, the Federal Reserve Board or the International Monetary Fund.

${ }^{\dagger}$ Research Department, Federal Reserve Bank of St. Louis.

Email: luciana.juvenal@stls.frb.org (http://lucianajuvenal.com)

${ }^{\ddagger}$ Department of Economics and Related Studies, University of York.

Email: paulo.santosmonteiro@york.ac.uk (https://sites.google.com/site/smontpaulo/) 


\section{Introduction}

Empirical work using micro-level data on firms has documented the superior performance characteristics of exporters relative to non-exporters. The cross-sectional differences between exporters and non-exporters are large, but they do not inform the direction of the causality between exporting and superior performance. Exporters may perform better because the good firms become exporters, or because exporting is good for firms, or both. Bernard and Jensen (1999) disentangle these effects and present evidence that only the relatively bigger and more productive firms become exporters. However, in their analysis, the evidence on the benefits of exporting on firm performance is mixed.

In this paper, we analyze the relation between exporting and firm performance focusing on a key question: Is diversification of export markets good for firms? In order to address this question, we propose a structural model of trade and investment in technology adoption when firms face demand uncertainty in their foreign markets. Our theory is based on the premise that exporting to several markets reduces demand uncertainty and, hence, raises incentives to invest in productivity improvements.

The few existing theories of the within-firm productivity growth and trade nexus concentrate on the relationship between the incentives to invest in process innovation and the overall volume of sales. Process innovation requires an up-front fixed cost in return for a reduction in marginal costs. In turn, lower trade costs raise exporter's sales and for some exporters this tips the balance in favor of adopting better technologies. Examples of these models have been recently developed in Lileeva and Trefler (2010) and Bustos (2011).

In our set-up, process innovation also requires an up-front fixed cost in return for a reduction in marginal costs. However, unlike the existing theories, better access to export markets raises the incentives to invest in process innovation even after controlling for market size. This happens because export market diversification lowers demand uncertainty, thus raising the expected benefit of investing in the reduction of marginal costs through process innovation. In the proposed model, export market diversification and not just market size are conducive to process innovation. Expansion into multiple export markets can induce firms to upgrade technology for reasons which are unrelated to increases in the scale of production.

In our model, the salient form of heterogeneity across firms comes from the cost of investing in process innovation. ${ }^{1}$ We assume this cost is firm specific and a function of observable variables such as the firm's age and the volume of sales, and an unobservable idiosyncratic factor. Allowing for the cost of adoption to vary with the firm's characteristics is important because there is evidence that the choice to invest in productivity improvements depends on

\footnotetext{
${ }^{1} \mathrm{We}$ focus on the decision to invest in productivity improvements and take as given the choice of firms to export or not, and which countries to export to. The latter could be modeled using, for example, the framework in Melitz (2003) and its extension in Chaney (2008), or models which explicitly consider the endogenous formation of trade networks as in Chaney (2011).
} 
firm's performance. ${ }^{2}$ The benefits of adopting a better technology vary endogenously with the firm's overall market size and the number of distinct markets served by the firm.

The upshot is that the structural model takes the form of a discrete choice model of technology adoption for which the selection equation depends on observable variables affecting the firm's adoption cost, and on the firm's idiosyncratic factor. This selection equation yields a very tractable likelihood function and the structural model can be estimated by Maximum Likelihood. The key structural parameter to be estimated controls how an increase in the number of foreign markets affects the threshold adoption cost below which firms invest in productivity improvements. We estimate the structural model using a large sample of Argentinean manufacturing exporters obtained from detailed firm-level customs data. We find that export market diversification increases the likelihood of technology adoption.

An important feature of our model is that it makes predictions about the functional form of the relationship between the number of export market destinations and firm's performance. Increasing the number of export destinations lowers the volatility of demand. However, if the firm customer base is already well diversified, serving an additional foreign market does not have a big impact on volatility and does not affect strongly the incentives to invest in productivity improvements. Thus, the incentives to adopt better technologies are larger in the early stages of firms' expansion into foreign markets. When we allow for this nonlinearity we find that, starting from a single destination, exporting to an additional destination lowers the standard deviation of total export sales by almost $2 \%$. This finding is consistent with evidence in Buch, Dopke, and Strotmann (2009), who use comprehensive data on more than 21,000 German manufacturing firms for the period between 1980 and 2001, and report that increased export openness lowers firm-level output volatility and that this effect is primarily driven by variations along the extensive margin (exporters compared to non-exporters).

The hypothesis that exports, through market diversification, stabilize firm's sales and that the larger the spread of firm's exports over several markets the less demand uncertainty they face, goes at least back to Hirsch and Lev (1971). In a related study, Guiso and Parigi (1999) investigate the effects of uncertainty on the investment decisions of a sample of Italian manufacturing firms. They use information on the subjective probability distribution of future demand for firms' products according to entrepreneurs. Their results support the view that uncertainty weakens the response of investment to demand, therefore slowing down capital accumulation. If export market diversification reduces firms' demand uncertainty, then it follows from the findings of Guiso and Parigi (1999) that better access to foreign markets should raise the incentives to invest in productivity improvements, particularly when the investment cost is sunk as is usually assumed in the trade and investment literature. This is a main motivation for the current paper.

\footnotetext{
${ }^{2}$ For instance, Aw et al. (2011) using plant-level data for the Taiwanese electronics industry find evidence that high productivity plants simultaneously self-select into investment in R\&D activities and exporting.
} 
There are very few papers examining productivity gains from entering export markets by distinguishing between various destinations. One example is De Loecker (2007), who looks at Slovenian firm level data, and finds that the number of export destinations and productivity are positively correlated. ${ }^{3}$ This finding is consistent with our model of technology adoption under uncertainty, but it is also consistent with more productive firms being able to overcome higher fixed costs when there are market specific fixed costs of export entry. Due to the possibility of reverse causality, the relationship between firm performance and the number of export markets served must be interpreted carefully. In order to overcome the identification challenge, we estimate the role played by export market diversification using complementary empirical approaches. These include OLS regressions, structural estimation of our theoretical model and, finally, matching techniques to estimate the causal effect that varying the number of export markets exerts on firm performance.

When we use matching techniques, we match firms' treatment and control groups according to their exporting experience previous to treatment. ${ }^{4}$ Each treatment is defined as raising the number of export destinations by one unit, starting from different initial number of export markets. The treatments are specified in a way that allows for the identification of the nonlinear relationship between firms' performance and diversification. Consistent with our theory, the average treatment effect on the treated firms is larger when the number of destinations is raised from a single destination to two destinations. By exploiting the fact that we have a panel with data about firms' access to each foreign market starting in 2002 and extending until 2009, we check our identification strategy with Placebo specifications: We show that export diversification in subsequent years (defined in terms of the same narrow treatments) does not affect the performance of the firms in the baseline year.

The remainder of the paper is organized as follows. Section 2 describes the model set-up and Section 3 derives the likelihood function of the model used for the structural estimation. Section 4 describes the data and OLS estimation. The maximum likelihood estimates are discussed in Section 5 and Section 6 considers the propensity score matching results. Finally, Section 7 concludes.

\footnotetext{
${ }^{3}$ De Loecker (2007) finds that exporting to high income countries raises the productivity of the exporting firm by more than when the firm exports to poor countries. He interprets this finding as supporting evidence for the hypothesis that firms learn by exporting. However, it is interesting to notice that because poor countries have more volatile aggregate income than rich countries (see for instance Koren and Tenreyro, 2007), exporting to poor countries also contributes less towards the reduction of export sales volatility than exporting to rich countries. Thus, our (risk-based) theory of productivity improvements is also consistent with the finding that exporting to poor countries contributes less to improve the productivity of the exporting firm.

${ }^{4}$ Albornoz et al. (2012) suggest that exporting experience is an important predictor of future firm performance and is, therefore, a potential confounding factor.
} 


\section{Model Set-up}

The world economy consists of a continuum of locations in the interval $[0, \bar{n}]$, where $\bar{n}$ is a finite and positive integer. ${ }^{5}$ We consider the problem of the firms located on the origin of the real line (the domestic firms). The domestic wage is the numéraire.

Demand - Each domestic firm $j$ is the monopolistic supplier of a differentiated commodity. If the firm $j$ trades with location $x$, it faces from that location the following isoelastic demand function

$$
p_{j}(x)=\left[e(x) f_{j}(x) / q_{j}(x)\right]^{1 / \sigma}
$$

with $\sigma>1$ the elasticity of substitution, and where $f_{j}(x)$ is the mass of customers the firm serves in location $x$, and $p_{j}(x)$ and $q_{j}(x)$ are, respectively, the price of commodity $j$ in location $x$ and the quantity demanded by each customer in location $x$. The random variable $e(x)$ is an exogenous demand-shifter with positive support. The total mass of customers served by firm $j$ is given by

$$
m_{j}=\int_{0}^{\bar{n}} f_{j}(x) d x .
$$

The line $[0, \bar{n}]$ is segmented into $\bar{n}+1$ distinct countries. Location 0 corresponds to the domestic economy and the other $\bar{n}$ countries each have length 1 . Thus, country 1 corresponds to the locations in the interval $(0,1]$, country 2 corresponds to the locations in the interval $(1,2]$ and successively, so that country $n$ corresponds to the locations in $(n-1, n]$. The exogenous demand shocks are country specific and, hence, $e(x)=e_{n}$, for all locations $x \in$ $(n-1, n]$. The shocks $e_{n}$ are identically and independently distributed across countries, with mean $\mu$ and variance $\sigma_{e}^{2}$.

Technology - There exist two technologies that are available to each firm that are labeled 0 and 1 , respectively, and both are characterized by a diminishing returns to scale production function of the form

$$
Q_{j}=B_{i} L_{j}^{\alpha}, \quad i=0,1, \alpha \in(0,1) \text { and } B_{i}>0
$$

where $L_{j}$ is the quantity of labor used by firm $j$ to produce total output $Q_{j}=\int_{0}^{n} q_{j}(x) d x$. $B_{0}<B_{1}$, meaning that technology 0 is less efficient than technology 1 . However, adopting the more efficient technology requires the payment of a firm specific sunk investment $\operatorname{cost} C_{j}{ }^{6}$

\footnotetext{
${ }^{5}$ The geography of the world economy is as in the model of Chaney (2011) who develops a theory of dynamic entry of firms into foreign markets, in which firms both directly search for foreign trading partners and also use their existing network of contacts to remotely search for new partners. However, we do not wish to examine the endogenous formation of trade networks (the focus of Chaney's paper) and, instead, assume random search across countries without geographic biases.

${ }^{6}$ There are many plausible reasons for assuming that the cost of investing in the adoption of the more efficient technology differs across firms. For example, it is well known that the costs of external financing vary widely across firms (Hennessy and Whited, 2007). Different financing costs will imply differences in the cost of investing in technology upgrading.
} 
The profits of a firm endowed with the cost parameter $C_{j}$ are

$$
\begin{aligned}
& \pi_{j}^{0}=\kappa\left[B_{0}^{\sigma-1} \sum_{n=1}^{\bar{n}} e_{n} \int_{n-1}^{n} f_{j}(x) d x\right]^{\eta}, \quad \text { if technology } 0 \text { is adopted and } \\
& \pi_{j}^{1}=\kappa\left[B_{1}^{\sigma-1} \sum_{n=1}^{\bar{n}} e_{n} \int_{n-1}^{n} f_{j}(x) d x\right]^{\eta}-C_{j}, \quad \text { if technology } 1 \text { is adopted, }
\end{aligned}
$$

with $\eta=[(1-\alpha) \sigma+\alpha]^{-1} \in(0,1)$ and $\kappa$ a positive parameter. ${ }^{7}$

The firm must decide whether to adopt the more efficient technology before the uncertainty about foreign demand is resolved. Thus, the problem solved by the firm is

$$
\max _{\text {adopt }, \text { don't }}\left\{\mathbb{E}\left(\pi_{j}^{0}\right), \mathbb{E}\left(\pi_{j}^{1}\right)\right\}
$$

where $\mathbb{E}$ denotes the expectation operator. The upshot is that firm $j$ decides to adopt the more efficient technology if

$$
\left(A_{1}-A_{0}\right) \mathbb{E}\left[\left(\sum_{n=1}^{\bar{n}} e_{n} \int_{n-1}^{n} f_{j}(x) d x\right)^{\eta}\right]-C_{j} \geq 0,
$$

where $A_{i}=B_{i}^{(\sigma-1) \eta}$, and the term $\left(A_{1}-A_{0}\right)>0$ reflects the efficiency gains from the adoption of technology 1 .

In turn, the term inside the expectation operator is a weighted average of the demand shocks from each foreign country. We assume there is no geographic bias in the formation of contact networks: if the firm has contacts in $\bar{n}_{j}$ distinct countries, there is a probability $\bar{n}_{j}^{-1}$ that a contact is located in a given country, and those probabilities are independent across contacts. ${ }^{8}$ The upshot is that if a firm has $m_{j}$ contacts distributed across $\bar{n}_{j}$ distinct countries, then for large $m_{j}$ the firm will have $m_{j} / \bar{n}_{j}$ distinct contacts in each country with whom it trades. Thus, we are able to reexpress the term inside the expectation operator as

$$
\mathbb{E}\left[\left(\sum_{n=1}^{\bar{n}} e_{n} \int_{n-1}^{n} f_{j}(x) d x\right)^{\eta}\right]=\mathbb{E}\left[\left(m_{j} \sum_{n \in \Omega_{j}} \frac{e_{n}}{\bar{n}_{j}}\right)^{\eta}\right],
$$

where $\Omega_{j}$ denotes the list of countries that firm $j$ exports to. ${ }^{9}$ We are now ready to establish

\footnotetext{
${ }^{7} \kappa=(1+\alpha / \sigma-\alpha)(\alpha-\alpha / \sigma)^{(\sigma-1) \alpha /(\sigma-\alpha \sigma+\alpha)}>0$. See Appendix A for the detailed derivation of the profit functions.

${ }^{8}$ In the empirical investigation we propose constructing an adjusted measure of the number of export destinations that captures more precisely the effective contribution toward diversification of each destination.

${ }^{9}$ See Appendix B for details.
} 


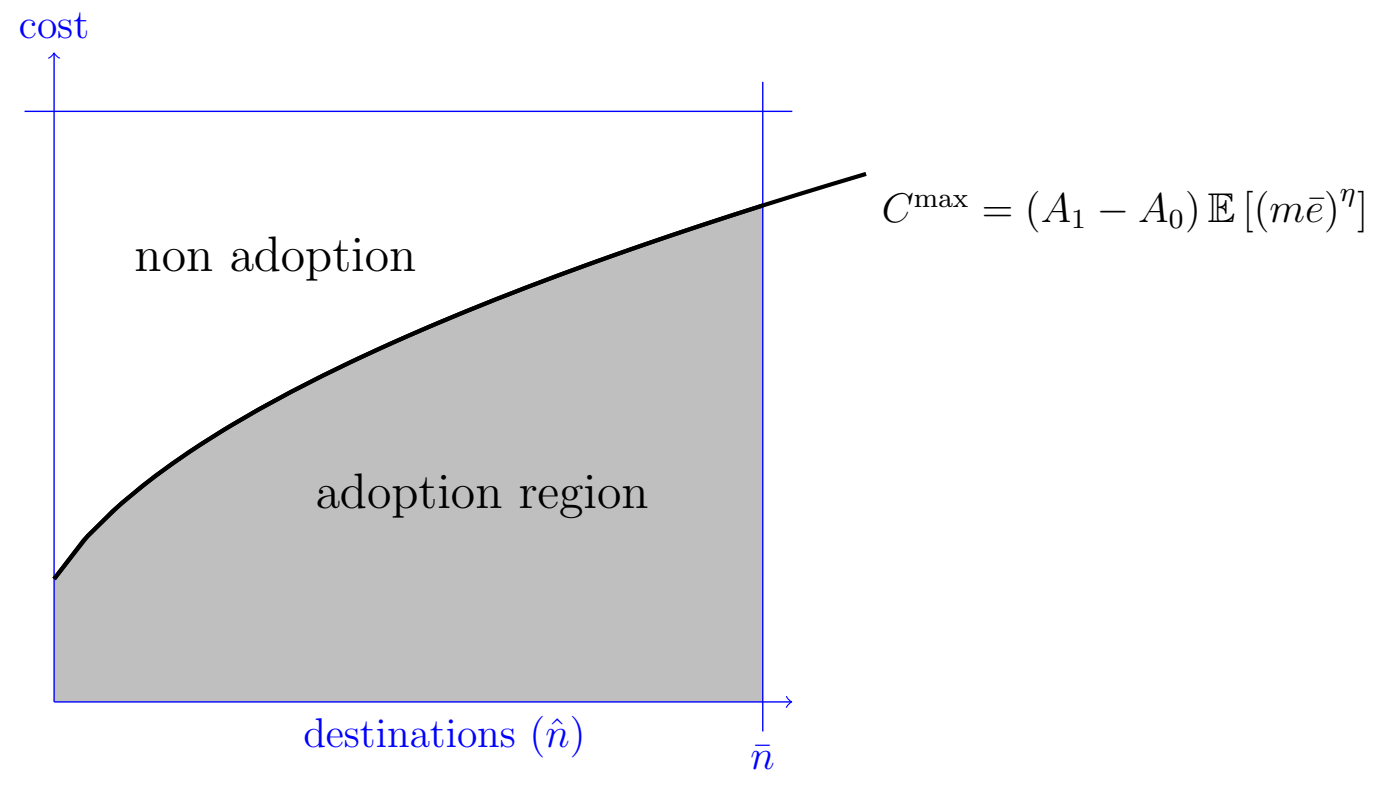

Figure 1: Diversification and technology adoption.

an important result for the sequel. Recall that the shocks $e_{n}$ are identical and independently distributed with mean $\mu$ and variance $\sigma_{e}^{2}$. Therefore, the random variable

$$
\bar{e}_{j}=\sum_{n \in \Omega_{j}} \frac{e_{n}}{\bar{n}_{j}},
$$

behaves as a sample average and, hence, it follows from the central limit theorem (CLT) that $\bar{e}$ is approximately normally distributed with mean $\mu$ and variance $\sigma_{e}^{2} / \bar{n}_{j} .{ }^{10}$ Hereafter, we refer to $\bar{e}$ as the firm's perceived demand. We establish the following Proposition

Proposition 1. Consider two firms that adopt the same technology and have the same total mass of contacts $m$ (assumed to be large). Then, the firm that exports to more destinations faces less demand uncertainty.

The Proof of Proposition 1 is in Appendix B. In turn, the relationship between export market diversification and demand uncertainty allows us to establish the relationship between export diversification and technology adoption.

Proposition 2. Consider two firms having the same total mass of contacts $m$ (assumed to be large). Then, the maximum adoption cost $C^{\text {max }}$ at which the firm chooses to adopt the better technology is higher for the firm that exports to more destinations.

\footnotetext{
${ }^{10}$ We do not need to apply the CLT if we make the additional assumption that the country specific shocks $\bar{e}_{j}$ are identically and independently drawn from an approximately normal distribution with mean $\mu$ and variance $\sigma_{e}^{2}$.
} 
The proof of Proposition 2 is in Appendix D and relies on a simple application of Jensen's inequality, but the result is best understood by inspecting Figure 1. Consider all firms having same mass of total contacts $m$. The black curve $C^{\max }=\left(A_{1}-A_{0}\right) \mathbb{E}\left[(m \bar{e})^{\eta}\right]$ depicts the maximum cost at which firms choose to adopt the more efficient technology. ${ }^{11}$ Firms are each characterized by an adoption cost and a number of export destinations. Those located in the gray region choose to adopt the more efficient technology. The other firms do not. The maximum cost at which firms adopt the better technology is increasing in the number of destinations. The reason is that firms exporting to more destinations face less demand uncertainty, which raises the expected benefits from adopting the more efficient technology. The adoption set is convex because the gains from diversification are smaller for each additional export destination market.

Conditional firm size distribution-Following the adoption decision, the demand shocks $e_{n}$ are realized and each firm must decide how much labor to hire. The employment level set by a firm that adopts technology $i$ and has $m$ contacts spread across $\bar{n}_{j}$ countries is given by

$$
L_{j}\left(i, m_{j}, \bar{n}_{j}\right)=\left[(\rho \alpha)^{\sigma} B_{i}^{\sigma-1} m_{j} \bar{e}_{j}\right]^{\eta}
$$

Thus, the first testable prediction implied by Proposition 2 is that, conditional on the number of contacts $m$ and the cost of adoption $C_{j}$, firms that export to more destinations are on average larger than firms exporting to fewer destinations. The reason is simply that the later are less likely to adopt the better technology.

In the sequel we define the variable

$$
\begin{aligned}
\operatorname{SIZE} & =\left[\frac{(\rho \alpha)^{-\sigma} L_{j}^{1 / \eta}}{m_{j}}\right] \\
& =B_{i}^{\sigma-1} \bar{e}_{j},
\end{aligned}
$$

where the second equality is obtained by using (7) to substitute for $L_{j}$. The crucial step to estimate the structural model in what follows, is to treat size as an observed variable. To do this, the parameters $\sigma$ and $\alpha$ are calibrated and assumed known when conducting the model's structural estimation. In turn, the variable $m$, which corresponds to the total number of customers served by the firm $j$ is proxied by the total sales of the firm which we observe in our data. ${ }^{12}$ Since we also observe $L_{j}$ (employment in firm $j$ ), the upshot is that $(\mathrm{SIZE})_{j}$ can be obtained from the data directly using Equation (8).

Because the variable $\bar{e}_{j}$ is approximately normally distributed with mean $\mu$ and variance

\footnotetext{
${ }^{11}$ Given by the cost $C$ at which equation (5) holds as an equality.

${ }^{12}$ Given the assumed CES demand system, the total sales (FOB) are proportional to the number of clients and, therefore, we use FOB as a proxy for $m$.
} 
$\sigma_{e}^{2} / \bar{n}_{j}$, it follows that the size distribution conditional on the choice of technology $i$ is also approximately normal, given by

$$
\operatorname{SIZE} \mid i, \bar{n}_{j} \sim N\left(B_{i}^{\sigma-1} \mu,\left(B_{i}^{\sigma-1}\right)^{2} \frac{\sigma_{e}^{2}}{\bar{n}_{j}}\right)
$$

In Section 3 that follows, we obtain the model's likelihood function based on (9) and a conditional distribution for the adoption $\operatorname{cost} C_{j}$.

\section{Likelihood Function}

To construct the model's likelihood function we need to model the conditional distribution of the firm specific adoption cost $C_{j}$. We assume that the adoption cost is a function of observable characteristics including the age of the firm, labeled $(\mathrm{AGE})_{j}$, and the total annual value of exports, labeled (FOB), plus a random component

$$
\ln (C)_{j}=\alpha_{0}+\alpha_{1}(\mathrm{AGE})_{j}+\alpha_{2} \ln (\mathrm{FOB})_{j}+\varepsilon_{j},
$$

where $\varepsilon_{j}$ is assumed to have the standard normal distribution. ${ }^{13}$ In turn, the log of the maximum cost at which firms choose to adopt the better technology turns out to be a function of the number of export destinations $(\mathrm{DEST})_{j}$ and the total annual value of exports $(\mathrm{FOB})_{j}$, and can be expressed as follows ${ }^{14}$

$$
\ln \left(C^{\mathrm{max}}\right)_{j} \approx \phi_{0}+\phi_{1} \ln (\mathrm{FOB})_{j}+\phi_{2}\left(\frac{1}{\mathrm{DEST}}\right)_{j} .
$$

with $\phi_{0}>0, \phi_{1}>0$ and $\phi_{2}<0$. The upshot is that the technology adoption choice can be modeled using a simple selection model based on the latent variable

$$
\begin{aligned}
Z_{j} & =\ln (C)_{j}-\ln \left(C^{\mathrm{max}}\right)_{j} \\
& =\varphi_{0}+\varphi_{1}(\mathrm{AGE})_{j}+\varphi_{2} \ln (\mathrm{FOB})_{j}+\varphi_{3}\left(\frac{1}{\mathrm{DEST}}\right)_{j}+\varepsilon_{j},
\end{aligned}
$$

\footnotetext{
${ }^{13}$ As argued in Footnote 6, the cost of investing in productivity improvements is likely to depend on the firm's characteristics such as size and age. Aw et al. (2011) find that high-productivity firms have particularly large benefits from R\&D investment. One way to allow for size to vary net of benefits from investment in productivity improvements is by modelling the cost of adoption to depend on firm's characteristics, as we do here.

${ }^{14}$ Equation (11) is obtained from condition (5). The detailed derivation is made in Appendix C.
} 
where $\varphi_{0}=\alpha_{0}-\phi_{0}, \varphi_{1}=\alpha_{1}, \varphi_{2}=\alpha_{2}-\phi_{1}$ and $\varphi_{3}=-\phi_{2}$, with elements collected in the parameter vector $\varphi$. The technology adoption satisfies the selection equation

$$
\text { technology adopted by firm } j=\left\{\begin{array}{lll}
0 & \text { if } & Z_{j}>0 \\
1 & \text { if } \quad Z_{j} \leq 0
\end{array}\right. \text {. }
$$

Referring once again to Figure 1, the selection equation (13) implies that firms for which $Z_{j} \leq 0$ belong to the adoption region (gray region) and, instead, firms for which $Z_{j}>0$ belong to the non adoption region, with $Z_{j}$ a function of the observable variables $(\operatorname{AGE})_{j}$, $(\mathrm{FOB})_{j}$ and $(\mathrm{DEST})_{j}$. Recalling that $\varepsilon_{j}$ is standard normal distributed, it follows that the probability of firm $j$ operating with technology $i$ conditional on the observables is given by

$$
\mathbb{P}(\text { technology } i \mid \text { AGE, FOB, DEST })=\left\{\begin{array}{ll}
1-\Phi\left(-\tilde{Z}_{j}\right) & \text { for technology } 0 \\
\Phi\left(-\tilde{Z}_{j}\right) & \text { for technology } 1
\end{array},\right.
$$

with $\Phi$ denoting the cumulative standard normal distribution function and

$$
\tilde{Z}_{j}=\varphi_{0}+\varphi_{1}(\mathrm{AGE})_{j}+\varphi_{2} \ln (\mathrm{FOB})_{j}+\varphi_{3}\left(\frac{1}{\mathrm{DEST}}\right)_{j} .
$$

To construct the likelihood function of the model we begin by making use of (9) to obtain the probability of the firm's $(\mathrm{SIzE})_{j}$ conditional on the technology choice $i$, which is given by

$$
\mathbb{P}(\text { SIZE } \mid \text { technology } i, \text { DEST } ; \Theta)=\left(\sqrt{2 \pi / \bar{n}_{j}} B_{i}^{\sigma-1} \sigma_{e}\right)^{-1} \exp \left[-\frac{\bar{n}_{j}}{2}\left(\frac{\operatorname{SIZE}-B_{i}^{\sigma-1} \mu}{B_{i}^{\sigma-1} \sigma_{e}}\right)^{2}\right]
$$

where $\Theta=\left(\mu, \sigma_{e}, \varphi\right)$ is the vector of structural parameters to be estimated. ${ }^{15}$

Finally, if we assume that the total demands facing each firm are roughly independent and combine (14) with (16) we can construct the likelihood function as

$$
\mathcal{L}(\Theta \mid \text { SIZE, AGE, FOB, DEST })=\prod_{j}\left\{\begin{array}{ll}
\sum_{i=0}^{1} & \left(\sqrt{2 \pi / \bar{n}_{j}} B_{i}^{\sigma-1} \sigma_{e}\right)^{-1} \exp \left[-\frac{\bar{n}_{j}}{2}\left(\frac{\mathrm{SIZE}-B_{i}^{\sigma-1} \mu}{B_{i}^{\sigma-1} \sigma_{e}}\right)^{2}\right] \\
\times \mathbb{P}(\text { technology } i \mid \text { AGE, FOB, DEST })
\end{array}\right\}
$$

with $j$ indexing the sample observation.

\footnotetext{
${ }^{15} B_{0}$ is not separately identified from $B_{1}$ and $\mu$ and so we set it equal to unity without loss of generality. The parameter $B_{1}$ can in principle be identified, but the maximum likelihood estimates are too sensitive to changes in the initial conditions if $B_{1}$ is left as a free parameter. Therefore, we also calibrate $B_{1}$ in Section 5 . The parameters $\alpha$ and $\sigma$ are also fixed at standard values found in the literature.
} 


\section{Data and OLS Estimates}

We use firm level export data for Argentinean manufacturing exporters collected by the Argentinean customs and provided by a private vendor named Nosis. ${ }^{16}$ The overall sample available to us extends between the 2002-2009 period. For each firm, we observe the total value (in US dollars) of its FOB exports to each destination country. We also have each firm's number of employees in 2007, the firm's sectoral classification and the firm's creation date. ${ }^{17}$ Finally, for most firms, we also have information about firms' total sales in $2007 .{ }^{18}$

We restrict our analysis to manufacturing firms and by combining these data we obtain our main sample, that consists of an unbalanced panel of 5,395 firms for which we observe the age, the 4-digit sectoral classification, the number of export destinations and the value of exports to each destination for the 2002-2009 period, matched with information about each firm's total number of employees for the 2007 cross-section. $^{19}$ In addition, we have information about the firm's total sales in 2007 for 5,055 firms of the manufacturing firms in the sample.

Table 1 shows descriptive statistics for the 5,395 manufacturing firms in our main sample. Firms export on average to 5 destinations, have an average size of 109 employees and have 23 years of age. However, the median firm exports to just 2 destinations, has 30 employees and is 19 years old. Thus, both the destination and the size distribution of firms is characterized by positive skewness. To show the effect of age on the location and shape of the destination and the size distribution of firms, Table 1 also reports the mean and the median across different age groups. The average size of the firm and the average number of export destinations is increasing with the age of the firm.

\footnotetext{
${ }^{16}$ In Argentina the National Statistics Office (INDEC) is not allowed to reveal data at the firm level (this is established in Law 17,622). We tried to obtain the data directly from the INDEC but our request was denied. Nosis buys the data directly from Argentinean customs and combines their own market knowledge with an algorithm that compares export transactions. When the exporter names are not available, they use earlier transactions that include the names in order to generate a "probable exporter" . For instance, if an export transaction in 2007 had similar port, Harmonized Tariff Schedule (HTS), volume, and destination information as several of firm X's export transactions from a previous year, the algorithm would list firm X as the "probable exporter" in 2007.

${ }^{17}$ Nosis obtains this information from the firm's tax returns which are administered by the Argentine Tax Authority.

${ }^{18}$ In particular, firm's are distributed in six categories in terms of their total sales (invoicing): between 0 and 500 thousand dollars; 500-1,000 thousand dollars; 1,000-5,000 thousand dollars; 5,000-20,000 thousand dollars; 20,000-100,000 thousand dollars and finally sales greater than 100,000 thousand dollars.

${ }^{19}$ The 2007 cross-section includes 9,627 firms, of which 5,395 are manufacturing firms. However, only 2,545 manufacturing firms are present throughout the entire 2002-2009 period.
} 
Table 1: Descriptive Statistics

\begin{tabular}{|c|c|c|c|c|c|c|c|c|c|}
\hline & \multirow[b]{2}{*}{ Mean } & \multirow[b]{2}{*}{ S.D. } & \multirow[b]{2}{*}{ Min } & \multirow[b]{2}{*}{ Max } & \multicolumn{5}{|c|}{ Percentiles } \\
\hline & & & & & $10^{t h}$ & $25^{t h}$ & $50^{t h}$ & $75^{t h}$ & $90^{t h}$ \\
\hline \# of destinations & 5 & 6.808 & 1 & 107 & 1 & 1 & 2 & 6 & 11 \\
\hline \# of destinations adjusted & 3 & 2.592 & 1 & 39 & 1 & 1 & 2 & 3 & 5 \\
\hline \# of employees & 109 & 348.93 & 3 & 7100 & 3 & 10 & 30 & 80 & 210 \\
\hline \multirow[t]{2}{*}{ Firm's age } & 23 & 15.086 & 2 & 110 & 9 & 12 & 19 & 31 & 45 \\
\hline & & \multicolumn{2}{|c|}{$\underline{\mathrm{DEST}}$} & \multicolumn{3}{|c|}{$\underline{\text { ADJDEST }}$} & \multicolumn{3}{|c|}{ EMPLOYMENT } \\
\hline Age Group & & Mean & Med & & Mean & Med & & Mean & Med \\
\hline$\leq 5$ & & 2.85 & 2 & & 1.91 & 1 & & 42.41 & 21 \\
\hline $6-10$ & & 3.02 & 2 & & 1.87 & 1 & & 39.42 & 12 \\
\hline $11-20$ & & 4.28 & 2 & & 2.28 & 1 & & 75.68 & 26 \\
\hline$\geq 21$ & & 6.12 & 3 & & 2.92 & 2 & & 165.45 & 45 \\
\hline
\end{tabular}

Note: The sample includes 5,395 Argentinean exporting manufacturing firms sampled in the year 2007. S.D. denotes the standard deviation, and Med denotes the median.

\subsection{Alternative Measure of Diversification}

In the data description we measure the number of destinations (DEST) as informed by our model, which is the total number of countries a firm exports to in a certain year. ${ }^{20}$ For our empirical application, however, this measure of diversification does not account for the fact that a firm may export a small percentage of its total FOB to a given country. To give an extreme example, if a firm exports $99 \%$ of its FOB to one country and the remaining $1 \%$ to a second country, we would measure the number of destinations (DEST) as equal to two, but clearly this firm would not be diversified. By including as a destination a country that represents a negligible proportion of a firm's FOB we may be overestimating the measure of diversification. Therefore, we also consider an adjusted measure of destinations that excludes the countries that represent a small proportion of total FOB exports.

\footnotetext{
${ }^{20}$ Recall that in the theoretical part we assumed that there is no geographic bias in the formation of contact networks: if the firm has contacts in $\bar{n}_{j}$ distinct countries, there is a probability $n_{j}{ }^{-1}$ that a customer is located in a given country, and those probabilities are independent across contacts. The upshot is that if a firm has $m_{j}$ contacts distributed across $\bar{n}_{j}$ distinct countries, then for large $m_{j}$ the firm will have $m_{j} / \bar{n}_{j}$ distinct contacts in each country. In reality, contacts are unlikely to be uniformly distributed across countries and so in the empirical work we consider an alternative measure for the number of export destinations to try to correct for the existence of geographic biases in matching with costumers.
} 
Figure 2: Number of Destinations (two alternative measures)

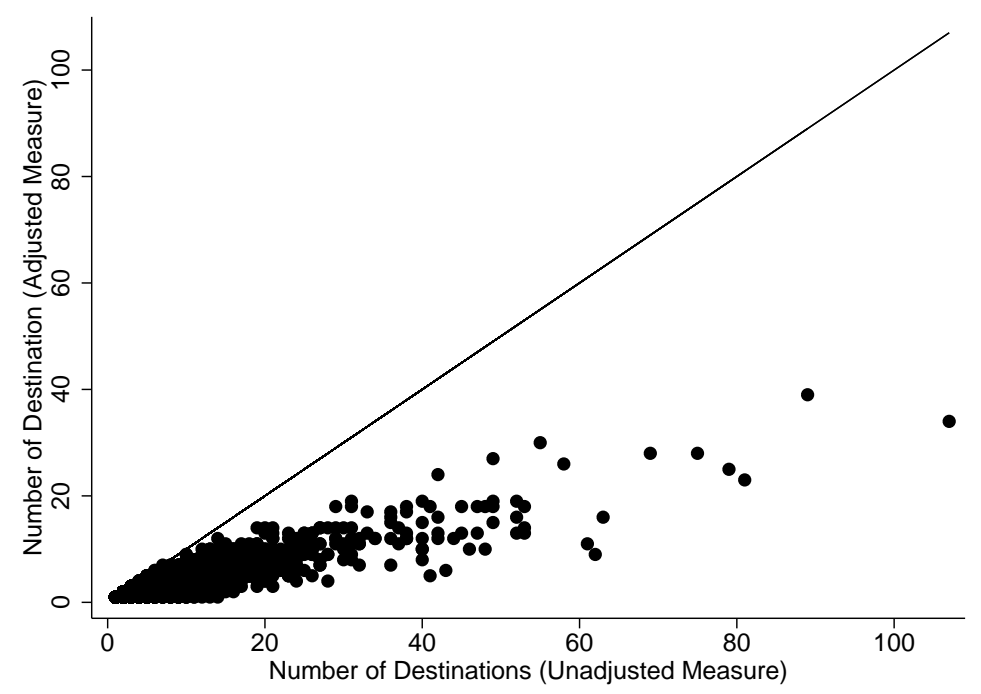

The adjusted measure that we propose excludes the destinations receiving exports whose value is less than half the firm's total FOB divided by the total number of destinations. ${ }^{21}$ In this way we only keep as a destination the countries that represent a significant proportion of the firm's total exports. Table 1 shows the descriptive statistics for the adjusted measure of destinations, ADJDEST, which suggests that firms export to an average of 3 (adjusted) destinations. This measure is also less volatile than DEST. The average number of adjusted export destinations increases with the age of the firm but at a smaller rate with respect to the unadjusted measure.

Figure 2 plots the adjusted against the unadjusted measure, respectively, ADJEST and DEST, in 2007. The Figure reveals that the difference between the two measures increases dramatically as the number of destinations is raised. Since there is a stark contrast between both measures, in the empirical Section we show results for both diversification measures.

\subsection{Diversification and Volatility}

The first Proposition advanced by our model is that the diversification of export markets tends to stabilize the firm's sales, so that the larger the spread of these exports over several markets the more stable the sales. A distinctive feature of our dataset is that we observe the firm's total exports over the period 2002-2009. We can, therefore, measure the volatility of each firm's sales by calculating the standard deviation of the total exports time series (in logs) for each firm. This measure of firm level volatility allows us to directly test Proposition 1

\footnotetext{
${ }^{21}$ Perfect diversification for a firm that exports to $\bar{n}$ destinations implies that each destination receives a fraction $1 / \bar{n}$ of the firm's total exports. We have tried several alternative measures and the empirical findings are robust to the different measures considered.
} 
Table 2: Diversification and Volatility

Dependent variable: std (ln FOB), 2002-2009 period

(1)

$(2)$

(3)

$(4)$

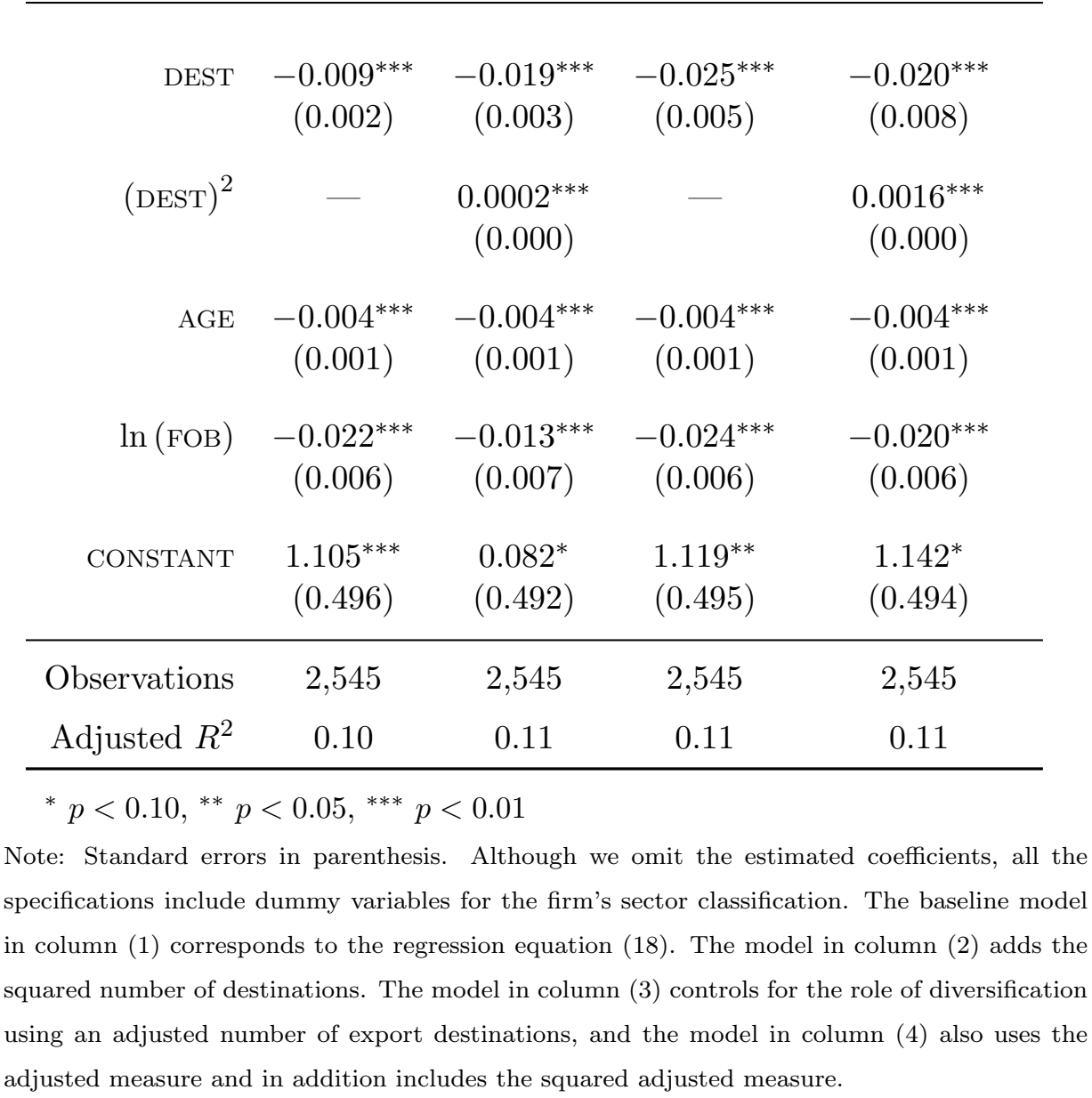

by estimating the following regression equation:

$$
\operatorname{std}(\ln \text { FOB })=\beta_{0}+\beta_{1}(\mathrm{DEST})+\beta_{2}(\mathrm{AGE})+\beta_{3} \ln (\mathrm{FOB})+\varepsilon,
$$

where std (ln $\mathrm{FOB})$ is the standard deviation of the logarithm of the firm's export volume in the 2002-2009 period, and (DEST) denotes the average number of export market destinations of the firm, over the same period. The covariates (AGE) and ln (FOB) are included to control for important firm characteristics such as firm's age and the volume of exports. The sample includes 2,545 firms, corresponding to the sample of manufacturing firms that are in the panel throughout the 2002-2009 period.

Table 2 reports the results from the estimation of equation (18). The first two columns report the regression estimates when we use the average number of destination countries as a measure of diversification, whereas the last two columns include the average number of 
destinations adjusted as described in Section 4.1 (which is likely to be a better measure of export market diversification). Finally, columns (1) and (3) only include linear terms and, instead, columns (2) and (4) include the squared number of destinations. The specifications (2) and (4) are important because they capture the fact that the relationship between diversification and volatility reduction is predicted to be concave: raising the number of export destinations lowers the volatility of demand but for each additional destination the reduction in volatility is smaller. ${ }^{22}$ All specifications include sectoral control dummies.

The findings are clearly in line with Proposition 1, with all the coefficients being precisely estimated. In particular, turning to column (1) we see that the coefficient $\beta_{1}$ has the expected negative sign, confirming the negative relationship between the number of export destinations and the volatility of sales. Using the baseline specification we obtain that exporting to one additional destination lowers the standard deviation of total exports by $1 \%$. As stated above, the association between diversification and sales stability is expected to be nonlinear (see the footnote 22). Therefore, in the specification of column (2) we estimate the regression equation (19) that includes the square of the number of export destinations. As predicted, in this specification the relationship between the number of export destinations and the volatility of sales is found to be concave: the reduction in volatility is smaller as the number of export market destinations increase. ${ }^{23}$

Another important finding emerges from the comparison of the specifications including the unadjusted diversification measure, columns (1) and (2), with the specifications including the adjusted measure, columns (3) and (4). The effect of raising the number of export destinations on the stabilization of total exports is stronger when we consider the adjusted measure. This finding is reassuring, because the adjusted measure is a superior measure of diversification and is probably plagued with fewer confounding factors. The differences across the two kinds of specification provide further evidence that diversification contributes to stabilize the export demand faced by firms.

Finally, across all specifications we find that firm's age has a stabilizing effect on exports. An

${ }^{22}$ The fluctuations to the firm's sales (in logarithms) are driven by the following stochastic component

$$
\nu \bar{e}_{j}=\nu \ln \left(\sum_{n \in \Omega_{j}} \frac{e_{n}}{\bar{n}_{j}}\right) .
$$

where the shocks $e_{n}$ are independently drawn from a distribution with mean $\mu$ and variance $\sigma_{e}^{2}$ (see Appendix B for details). Thus, the variance of $\bar{e}_{j}$ is given by $\operatorname{var}(\bar{e})=\sigma_{e}^{2} / \bar{n}_{j}$. The upshot is that $\partial \operatorname{var}(\bar{e}) / \partial \bar{n}_{j}<0$ and $\partial^{2} \operatorname{var}(\bar{e}) / \partial \bar{n}_{j}^{2}>0$. This means that raising the number of export destinations lowers the volatility of demand but for each additional destination the decrease in volatility becomes smaller. In columns (2) and (4) of Table 2 we, hence, estimate the regression equation

$$
\operatorname{std}(\mathrm{FOB})=\beta_{0}+\beta_{1}(\mathrm{DEST})+\beta_{2}(\mathrm{DEST})^{2}+\beta_{3}(\mathrm{AGE})+\beta_{4} \ln (\mathrm{FOB})+\varepsilon .
$$

with the coefficient $\beta_{1}$ predicted to be negative and the coefficient $\beta_{2}$ predicted to be positive.

${ }^{23}$ Thus, these empirical findings are consistent with the convex adoption region represented in Figure 1. 
increase in firm's age by 10 years reduces the standard deviation of FOB sales by around $4 \%$. The volatility of sales is also declining with the total level of exports. The estimated impact of the level of exports is halved in the specification of column (2) compared to the baseline specification. This may provide indication that there is collinearity between the unadjusted measure of export destinations and the size of the firm, consistent with the selection into export hypothesis. ${ }^{24}$

\subsection{Diversification and Performance}

We now seek to test Proposition 2 in the model. Proposition 2 states that, controlling for the total mass of customers, the firms that export to more countries will adopt the better technology for a wider range of the adoption cost. Testing Proposition 2 without a structural model is not easy because there are at least two important unobserved variables: First, we do not observe the firms' adoption cost $C_{j}$ and, second, we do not observe the technology adopted by the firm. Therefore, in Section 5 we estimate the structural model by maximum likelihood. Nevertheless, it is still informative to test some of the predictions implied by Proposition 2 using OLS regressions. For instance, by comparing the regression equation that includes the unadjusted measure of diversification to the one that uses the adjusted measure, we are able to identify the role of diversification free of several of the potential confounding factors.

\footnotetext{
${ }^{24}$ According to the selection into export hypothesis large firms are more likely to enter each export market.
} 
Table 3: Diversification and Firm's Performance: OLS regressions

\begin{tabular}{|c|c|c|c|c|}
\hline & \multicolumn{2}{|c|}{ Dependent variable: $\log$ (EMPL) } & \multicolumn{2}{|c|}{ Dependent variable: $\log$ (PROD) } \\
\hline & $(1)$ & $(2)$ & $(3)$ & $(4)$ \\
\hline DEST & $\begin{array}{c}0.0698^{* * *} \\
(0.004)\end{array}$ & $\begin{array}{c}0.1367^{* * *} \\
(0.011)\end{array}$ & $\begin{array}{c}0.2606^{* * *} \\
(0.007)\end{array}$ & $\begin{array}{c}0.4979^{* * *} \\
(0.019)\end{array}$ \\
\hline$(\mathrm{DEST})^{2}$ & $\begin{array}{c}-0.0006^{* * *} \\
(0.000)\end{array}$ & $\begin{array}{c}-0.0026^{* * *} \\
(0.001)\end{array}$ & $\begin{array}{c}-0.0030^{* * *} \\
(0.000)\end{array}$ & $\begin{array}{c}-0.0142^{* * *} \\
(0.001)\end{array}$ \\
\hline AGE & $\begin{array}{c}0.0169^{* * *} \\
(0.001)\end{array}$ & $\begin{array}{c}0.0181^{* * *} \\
(0.001)\end{array}$ & $\begin{array}{c}-0.0141^{* * *} \\
(0.002)\end{array}$ & $\begin{array}{c}-0.0100^{* * *} \\
(0.002)\end{array}$ \\
\hline MEDIUM SALES & $\begin{array}{c}1.3313^{* * *} \\
(0.053)\end{array}$ & $\begin{array}{c}1.3784^{* * *} \\
(0.053)\end{array}$ & $\begin{array}{c}-0.7336^{* * *} \\
(0.086)\end{array}$ & $\begin{array}{c}-0.5490^{* * *} \\
(0.091)\end{array}$ \\
\hline HIGH SALES & $\begin{array}{c}3.0872^{* * *} \\
(0.074)\end{array}$ & $\begin{array}{c}3.2849^{* * *} \\
(0.073)\end{array}$ & $\begin{array}{c}-1.0624^{* * *} \\
(0.122)\end{array}$ & $\begin{array}{c}-0.3711^{* * *} \\
(0.125)\end{array}$ \\
\hline CONSTANT & $\begin{array}{c}1.5408^{* * *} \\
(0.156)\end{array}$ & $\begin{array}{c}1.4078^{* * *} \\
(0.158)\end{array}$ & $\begin{array}{c}7.7004^{* * *} \\
(0.255)\end{array}$ & $\begin{array}{c}7.2467^{* * *} \\
(0.271)\end{array}$ \\
\hline Observations & 5,055 & 5,055 & 5,055 & 5,055 \\
\hline$R^{2}$ & 0.54 & 0.53 & 0.36 & 0.28 \\
\hline
\end{tabular}

Note: Standard errors in parenthesis. Columns (1) and (2) report the results corresponding to the regression equation (20) using employment as a measure of performance. Column (1) controls for the role of diversification using the number of export destinations while column (2) uses the adjusted measure of destinations. The columns (3) and (4) consider the same regression equation but using productivity as a measure of performance. The variables MEDIUM SALES and HIGH SALES are dummy variables capturing the firm's total volume of sales. Although we omit the estimated coefficients, all the specifications include dummy variables for the firm's sector classification at the four digit level.

Although we do not observe the firms' adoption cost, we have argued earlier that this cost is likely to be affected by factors such as firm's age and the total sales. Therefore, for the purpose of our OLS regressions, we can restate Proposition 2 as follows: Controlling for the age and total sales, firms that export to more destinations are more likely to adopt a better technology. Moreover, even if we do not observe the adoption choice, we know from equation (7) that for a given mass of total customers $m$, firms that adopt the more efficient technology employ more workers and are more productive. Thus, Proposition 2 implies that controlling for the age and total sales, firms that export to more destinations have in expectation higher employment and, also, higher productivity. 
To inspect these predictions we first estimate the following OLS regression:

$$
\text { PERFORMANCE }=\psi_{0}+\psi_{1}(\mathrm{DEST})+\psi_{2}(\mathrm{DEST})^{2}+\psi_{3}(\mathrm{AGE})+(\text { set of controls })+\varepsilon \text {. }
$$

The variable PERFORMANCE is either the logarithm of the firm's total number of employees or the logarithm of the firm's productivity. Our measure for productivity in this Section and throughout the paper is the ratio between the firm's total value (in US dollars) of its FOB exports to all destinations and the firm's total number of employees. The variable (DEST) denotes the number of export destinations in 2007. We also include in the baseline specification the squared number of destinations, (DEST) ${ }^{2}$, to account for the convexity of the adoption region implied by the model and consistent with the empirical results in Section 4.2. The regression equation includes age and dummy variables related to the level of the firm's total sales. ${ }^{25}$ All specifications include sectoral classification dummy variables (four digit $\mathrm{SIC})$.

Proposition 2 predicts that the coefficient $\psi_{1}$ should be positive and that the coefficient $\psi_{2}$ is negative, indicating that, even after controlling for the firm's total volume of sales, the maximum cost at which firms choose to adopt the better technology is increasing in the number of destinations but at a decreasing rate.

Table 3 reports OLS estimates of equation (20). The first two columns include the estimates using employment as a measure of performance and the last two columns include productivity. The estimates in columns (1) and (3) correspond to the baseline model, whereas the ones in columns (2) and (4) estimate the same regression using the alternative measure of number of destinations. The findings are all in line with the the predictions of the model. In particular, all the coefficients in the baseline specification have the expected sign and we find evidence of the nonlinear relationship between firm performance and the number of export destinations. We note that the coefficients $\psi_{1}$ has the expected positive sign and $\psi_{2}$ is negative. Therefore, we find strong evidence in favor of the non-linear relationship between export-market diversification and firms' performance.

Finally, it is once again interesting to compare the specifications in columns (2) and (4), which use the adjusted measure of diversification, with the specifications that use the baseline measure in columns (1) and (3). Consistent with the findings in Section 4.2, the impact on firm performance of increased export-market diversification is stronger when we consider the adjusted measure of diversification. For the same reasons mentioned in the previous Section, this result provides further evidence that the diversification of risk is an important mechanism.

Given that we are controlling for the firm's total sales, our findings suggest that better access to export markets raises the incentives to invest in process innovation even after controlling

\footnotetext{
${ }^{25}$ We construct the dummy variable classifying the firm's sales as low, medium or high, based on the invoice variable which is described in Footnote 18.
} 
for the scale of production. Therefore, risk diversification emerges as an important channel through which better access to export markets raises the incentives for firms to invest in productivity improvements. However, there are many confounding factors that are likely to affect our findings. For this reason, in the next Section we consider a structural approach which is based on the estimation of the Likelihood Function described in Section 3.

\section{Maximum Likelihood Estimates}

In this Section we estimate the structural parameters of the selection model described by equations (12) and (13) by maximizing the (log) likelihood function which is derived in Section 3. As explained in Section 3, the parameters $\alpha, \sigma$ and $B_{1}$ are not estimated and, instead, are calibrated. We calibrate the labor income share, $\alpha$, to 0.67 (the standard choice) and the elasticity of substitution across goods, $\sigma$, to 3.80, which is the value used in Ghironi and Melitz (2005). This value of $\sigma$ also implies a markup over marginal cost equal to $\sigma /(\sigma-1)=33 \%$, which is within the range of available estimates. ${ }^{26}$ Finally, we set $B_{1}$ equal to 1.10 implying that adopting the new technology raises labor productivity by 10 percent based on evidence from the Survey of Manufacturing Technology documented by Mcguckin, Streitwieser, and Doms (1998). ${ }^{27}$ This choice of value is also consistent with evidence in Doms, Dunne, and Troske (1997) who also use data from the Survey of Manufacturing Technology and find that the wage premium for production worker employed by plants that use more advanced production technologies is 8 percent, after controlling for differences in workers' characteristics. Reasonable changes in this assumption (allowing productivity changes ranging between 5 and 20 percent) have no qualitative effects on the estimates.

Finally, to control for differences in employment across firms which are explained by sector specific factors, we regress the logarithm of employment on sector fixed effects and obtain the residuals of this regression. In the structural estimation, we use the exponential of these residuals as the measure of employment. ${ }^{28}$

The estimates are reported in Table 4. Given the stringent functional form assumptions made, the estimated structural parameters should be regarded as merely suggestive of the relationship between export market diversification and technology adoption. We are mostly

\footnotetext{
${ }^{26}$ See, for example, Hall (1988).

${ }^{27}$ Mcguckin, Streitwieser, and Doms (1998) examine the relationship between the use of advanced manufacturing technologies and productivity growth rates using data from the 1993 and 1988 Survey of Manufacturing Technology. They document that on average, productivity grew by $11.2 \%$ for plants moving up a technology class.

${ }^{28}$ We perform the regression$$
\log (\text { EMPLOYMENT })_{j}=\beta(\text { SECTOR FIXED EFFECT })+\mathcal{E}_{j}
$$

and use as the measure of employment (free of sector specific factors) the variable $(\mathrm{EMP})_{j}=\exp \left(\hat{\mathcal{E}}_{j}\right)$, where $\hat{\mathcal{E}}$ are the estimated residuals.
} 
Table 4: Maximum Likelihood Estimates

\begin{tabular}{crrrr}
\hline & \multicolumn{2}{c}{ Estimate } & & \multicolumn{2}{c}{$95 \%$ C.I. } \\
\cline { 2 - 2 }$\sigma_{e}^{2}$ & 0.0202 & & {$[-0.0433$} & $0.2601]$ \\
$\varphi_{0}$ & 515.4803 & & {$[505.9425$} & $522.3542]$ \\
$\varphi_{1}$ & -805.7364 & & {$[-807.1306$} & $-801.3785]$ \\
$\varphi_{2}$ & 590.3998 & & {$[587.4440$} & $591.8033]$ \\
$\varphi_{3}$ & 310.1960 & & {$[304.2796$} & $314.2658]$ \\
\hline Observations & & 5,395 & \\
Log-Likelihood & & -11867.44 & \\
\hline
\end{tabular}

Note: The confidence intervals are computed using bootstrap standard errors obtained using the Montecarlo method based on 1,000 bootstrap replications. The parameters $\alpha, \sigma$ and $B_{1}$ are fixed at $0.67,3.80$ and 1.1 respectively.

interested in the parameters of the selection model (15). In particular, we care about the sign of the coefficient $\varphi_{3}$ that determines the impact of an additional export market on the firm's likelihood of adopting the better technology. For the data to be consistent with the prediction that export market diversification increases the likelihood of technology adoption, the parameter $\varphi_{3}$ should be positive. ${ }^{29}$ The coefficients in Equation (15), corresponding to the conditional expectation of the latent factor that determines the adoption choice, are estimated as follows

$$
\tilde{Z}_{j}=515.48-805.74(\mathrm{AGE})_{j}+590.40 \ln (\mathrm{FOB})_{j}+310.20\left(\frac{1}{\mathrm{DEST}}\right)_{j} .
$$

The estimated parameter $\varphi_{3}$ is 310.20 and is statistically significant, consistent with the prediction that the likelihood of adoption is increasing in the number of export market destinations. The confidence intervals in Table 4 are bootstrapped using the Montecarlo method. ${ }^{30}$ Unfortunately, an alternative test based on the Likelihood-Ratio test statistic for the null hypothesis $\varphi_{3}=0$ is unable to reject the null. Thus, although the point estimates are consistent with the prediction of the model, the parameters of the selection equation are weakly identified and must be interpreted carefully.

\footnotetext{
${ }^{29}$ Recall that the smaller is $\tilde{Z}_{j}$ the larger is the probability of adoption.

${ }^{30}$ The bootstrap is based on the simulation of country specific shocks, $e_{n}$, from the normal distribution with mean $\hat{\mu}^{\mathrm{MLE}}$ and standard deviation $\hat{\sigma}_{e}^{\mathrm{MLE}}$ and firm specific shocks to the adoption cost, $\epsilon_{j}$, from the standard normal distribution.
} 
The parameter $\varphi_{1}$ is negative and statistically significant, implying that the idiosyncratic adoption cost is on average lower for older firms, which is consistent with the evidence about how the cost of financing investment varies with firm characteristics. The sign of the coefficients $\varphi_{0}$ and $\varphi_{2}$ predicted by theory is ambiguous and we are agnostic about it. Nonetheless, the fact that the parameter $\varphi_{2}$ is positive suggests that controlling for age and the number of export destination, firms with large volume of sales are less likely to adopt the better technology. ${ }^{31}$

Overall, the estimated parameters are consistent with the main hypothesis that improved access to foreign markets raises the incentives to invest in productivity improvements. The key structural parameter $\varphi_{3}$ is found to be positive and statistically significant, indicating that an increase in the number of foreign markets raises the likelihood of the firm adopting the better technology. The firm's age is also found to play an important role, as older firms face lower adoption costs and are therefore more likely to invest in technology improvements.

\section{Matching Estimates}

As we already emphasized, one needs to be cautious in interpreting the OLS estimates as causal. Evidence of self-selection, whereby better performing firms are more likely to enter new export markets, is ubiquitous. The structural estimation in Section 4 is helpful to get a better grasp of the role played by diversification. However, as we said earlier, the estimated structural parameters should be interpreted carefully, given the stringent functional form assumptions required. Therefore, in this Section we consider a third approach to estimate the causal effect of export-market diversification has on firm performance.

This Section considers matching techniques to correct for selection bias into different levels of export market diversification. To identify the causal effect of export market diversification on a firm's performance we narrowly define treatments and create control groups using propensity scores based on observed characteristics. We narrowly define three treatments and the respective controls as follows:

1. Comparing firms exporting to a single destination in 2005 and 2006, and which start exporting to two destinations in 2007 (Treatment 1), to a control group which exports to a single destination in all three years between 2005 to 2007.

2. Comparing firms exporting to two destinations in 2005 and 2006, and which start exporting to three destinations in 2007 (Treatment 2), to a control group which exports to two destinations in all three years between 2005 to 2007.

\footnotetext{
${ }^{31}$ This finding is perhaps unexpected and should be interpreted cautiously, however, we notice that it is consistent with the results from the OLS regressions in Table 3, where we found that productivity is lower for firms with a high volume of sales after controlling for the number of export destinations.
} 
3. Comparing firms exporting to three destinations in 2005 and 2006, and which start exporting to four destinations in 2007 (Treatment 3), to a control group which exports to three destinations in all three years between 2005 to 2007.

By narrowing down the sample to include only firms with the same exporting history in 2005 and 2006, we are restricting the treated and the control groups to have the same exporting experience previous to treatment. This feature of our specification is important to attenuate the bias from self-selection into treatment. Indeed, recent work by Albornoz et al. (2012) finds that exporting experience is an important predictor of success conditioning on selecting into exporting. ${ }^{32}$ Therefore, if we did not control for the exporting history, differences in performance between exporters and non-exporters could be a result of selfselection by firms who experimented and learned about their productivity as exporters. ${ }^{33}$ Once we have restricted the sample to include only firms with the same exporting history up to the year of treatment, we use propensity score matching (Rosenbaum and Rubin 1983,1984 ) to estimate the average treatment effect on the treated firms (those that started exporting to an additional destination in 2007).

In order to estimate the average treatment effect on the firms selected into treatment we need to obtain the counterfactual level of performance that the firm would have, on average, had it not been treated. More formally, let $t_{i}$ be an indicator variable that equals 1 if the firm $i$ starts exporting to an additional destination in 2007 and 0 otherwise, and $p_{i}^{1}$ and $p_{i}^{0}$ the performance of firm $i$ in 2007 if, respectively, treated and non-treated. The average treatment effect for firms selected into treatment, hereafter Diversification Premium (DP), is defined as

$$
\mathrm{DP}=\mathbb{E}\left[\left(p_{i}^{1}-p_{i}^{0}\right) \mid t_{i}=1\right]
$$

Of course, for those firms which are treated, we observe $p_{i}^{1}$ but not $p_{i}^{0}$. Therefore, we need to obtain a counterfactual estimate for $p_{i}^{0}$, the performance which a firm treated in 2007 would on average have achieved had it not been treated. To obtain this counterfactual performance measure we match firms by important characteristics such as firm's age, value of FOB shipments and the four digit SIC classification.

Formally, we calculate each firm's predicted propensity score and then use a Kernel matching

\footnotetext{
${ }^{32}$ These authors propose a model in which firms learn about their ability to export only after exporting takes place. The firms condition the decision to serve other destinations on this information. Thus, exporting history matters because the expansion into different export markets is sequential and conditional on earlier successes.

${ }^{33}$ For instance, in Treatment 1 the sample only includes firms who were exporters (to a single destination) at least since 2005 and continued exporting for 3 years, revealing that they were successful at exporting. Albornoz et al. (2012) find that after becoming an exporter for the first time and conditional on remaining an exporter, growth upon entry at both the intensive margin (the sales in the market) and the extensive margin (the number of markets served) is significantly higher in a firm's first foreign market than in its subsequent markets. Because we only include firms that successfully started serving their first foreign market for at least three years we are able to estimate average treatment effects which are conditional on successful experimentation.
} 
Table 5: Diversification Premium

\begin{tabular}{|c|c|c|}
\hline \multirow[b]{3}{*}{ Diversification Premium } & \multicolumn{2}{|c|}{ Treatment 1} \\
\hline & Employment & Productivity \\
\hline & $\begin{array}{c}0.2515^{* *} \\
(0.138)\end{array}$ & $\begin{array}{c}0.4591^{* *} \\
(0.197)\end{array}$ \\
\hline Observations & \multicolumn{2}{|c|}{1504} \\
\hline & \multicolumn{2}{|c|}{ Treatment 2} \\
\hline \multirow[b]{2}{*}{ Diversification Premium } & Employment & Productivity \\
\hline & $\begin{array}{l}0.0622 \\
(0.295)\end{array}$ & $\begin{array}{l}0.3311 \\
(0.369)\end{array}$ \\
\hline Observations & \multicolumn{2}{|c|}{680} \\
\hline & \multicolumn{2}{|c|}{ Treatment 3} \\
\hline & Employment & Productivity \\
\hline Diversification Premium & $\begin{array}{c}-0.3386 \\
(0.151)\end{array}$ & $\begin{array}{l}0.0846 \\
(0.467)\end{array}$ \\
\hline Observations & \multicolumn{2}{|c|}{366} \\
\hline
\end{tabular}

$* p<0.10, * * p<0.05, * * * p<0.01$

Note: Standard errors in parenthesis. The results show estimates of Diversification Premia defined in Equation (22). The variables used to compute the propensity score are the age of the firm, the squared age of the firm, the FOB value of exports in 2004 and a set of dummy variables for the industry classification at the 4-digit SIC level.

method in which each firm exporting to an additional destination is matched with a weighted average of all firm which form the control group, with weights that are inversely proportional to the distance between propensity scores of the treated firm and the control group. More precisely, the Kernel matching estimator for the diversification premium is given by:

$$
\widehat{\mathrm{DP}}=\frac{1}{\# \text { of treated firms }} \sum_{i \in \mathcal{G}_{T}}\left\{p_{i}^{1}-\frac{\sum_{j \in \mathcal{G}_{C}} p_{j}^{0} \mathcal{K}\left(\frac{s_{j}-s_{i}}{h_{n}}\right)}{\sum_{l \in \mathcal{G}_{C}} \mathcal{K}\left(\frac{s_{l}-s_{i}}{h_{n}}\right)}\right\}
$$

where $\mathcal{G}_{T}$ and $\mathcal{G}_{C}$ are the set of firms in the treatment and control group, respectively, $s_{i}$ denotes the propensity score for firm $i$, and $\mathcal{K}($.$) is the Epanechnikov Kernel and h_{n}$ is the bandwidth. 


\subsection{Matching Results}

Table 5 contains the baseline estimates of the diversification premium. As before, we look at two outcome variables, employment and average labor productivity. Consistent with theory, the diversification premium is higher when the number of foreign markets served increases from a single destination to two destinations. The diversification premium associated with Treatment 1, which is defined as moving from exporting to a single destination in 2005 and 2006, to exporting to two destinations in 2007, is positive and significant at the $5 \%$ level for both the employment and productivity specifications. In particular, employment in the firms that start exporting to two destinations grows $25 \%$ and labor productivity grows $46 \%$.

Instead, for firms that are already exporting to many destinations, raising the number of foreign markets does not lead to improvements in performance. The effects of diversification on performance are insignificant when we consider the Treatments 2 and 3 . This result is in line with the model presented in Section 2. In our model, the gains from diversification are larger at an early stage of diversification and decrease for each additional export destination market. Therefore, it is expected that the largest effect on firm performance will be observed for the firms having as baseline a small number of export destinations (those contained in Treatment 1), and that this effect will dissipate after. Inspecting Table 5, it must be noticed that the standard errors are much larger for the Treatments 2 and 3, because the sample size is substantially smaller for those two treatments. However, focusing on the point estimates, the predicted non-linear pattern emerges clearly.

The matching estimates provide further evidence that export diversification has a positive impact on firms' size and that the effect is larger at the earliest stage of diversification. Although the matching estimates are not directly comparable to the OLS estimates reported in Table 3, the effect of number of destinations on firm performance implied by the OLS regression are smaller than the ones suggested by the matching estimates.

\subsection{Regional Diversification}

Throughout the paper our measure of diversification refers to the total number of countries a firm exports to in a certain year. In this Section, we test the sensitivity of our results to an alternative measure of export market diversification based on the number of regions to which the firm is exporting. In particular, we group Argentina's export destinations into nine regions: Mercosur, Chile-Bolivia (which are neighbor countries that are not Mercosur members), South America excluding Mercosur members and Chile-Bolivia, Central America, NAFTA members, EU27, Other Europe, China, Australasia (excluding China), and Africa. If, for instance, business cycles are synchronized within these regions but not across regions, then the regional specification may capture the diversification phenomena better.

In Table 6 we present the matching results for the regional specification. We note that the standard errors are much smaller for the regional specification, even with fewer observations. 
Table 6: Diversification Premium (Regional Specification)

\begin{tabular}{|c|c|c|}
\hline & \multicolumn{2}{|c|}{ Treatment 1} \\
\hline & Employment & Productivity \\
\hline Diversification Premium & $\begin{array}{c}0.3192^{* *} \\
(0.121)\end{array}$ & $\begin{array}{c}0.6253^{* * *} \\
(0.175)\end{array}$ \\
\hline Observations & \multicolumn{2}{|c|}{650} \\
\hline & \multicolumn{2}{|c|}{ Treatment 2} \\
\hline & Employment & Productivity \\
\hline Diversification Premium & $\begin{array}{c}-0.1552 \\
(0.173)\end{array}$ & $\begin{array}{c}0.4898^{* *} \\
(0.226)\end{array}$ \\
\hline Observations & \multicolumn{2}{|c|}{253} \\
\hline
\end{tabular}

\begin{tabular}{|c|c|c|}
\hline & \multicolumn{2}{|c|}{ Treatment 3} \\
\hline \multirow[b]{2}{*}{ Diversification Premium } & Employment & Productivity \\
\hline & $\begin{array}{c}-0.0670 \\
(0.245)\end{array}$ & $\begin{array}{l}0.0503 \\
(0.266)\end{array}$ \\
\hline Observations & \multicolumn{2}{|c|}{121} \\
\hline \multicolumn{3}{|c|}{${ }^{*} p<0.10,{ }^{* *} p<0.05,{ }^{* * *} p<0.01$} \\
\hline
\end{tabular}

Thus, the regional specification seems to be a better measure of diversification, that leads to the diversification premium being more precisely estimated. The diversification premium associated with Treatment 1 , which is defined as moving from exporting to a single region in 2005 and 2006, to exporting to two regions in 2007, is positive and significant at the $5 \%$ level for the employment specification and at the $1 \%$ level when we measure performance using productivity. The growth in employment and in labor productivity resulting from the diversification are estimated at $32 \%$ and $63 \%$, respectively, and are larger than the ones found for the baseline specification.

Turning to Treatment 2, defined as moving from exporting to two regions in 2005 and 2006 to three regions in 2007 we find an insignificant effect on employment. By contrast, we find a $48 \%$ increase in the productivity of the treated firms, which statistically significant at the $5 \%$ level. Note that the value of the coefficient is smaller for Treatment 2 than for Treatment 1 , suggesting that the gains from diversification are decreasing with the number of destinations. Finally, in Treatment 3 we find no change in the productivity or employment of the treated 
Table 7: Diversification Premium (Placebo Effects)

\begin{tabular}{|c|c|c|}
\hline \multirow[b]{3}{*}{ Diversification Premium } & \multicolumn{2}{|c|}{ Placebo 1} \\
\hline & Employment & Productivity \\
\hline & $\begin{array}{c}-0.0940 \\
(0.172)\end{array}$ & $\begin{array}{l}0.1135 \\
(0.271)\end{array}$ \\
\hline \multirow[t]{3}{*}{ Observations } & \multicolumn{2}{|c|}{283} \\
\hline & \multicolumn{2}{|c|}{ Placebo 2} \\
\hline & Employment & Productivity \\
\hline Diversification Premium & $\begin{array}{l}0.2143 \\
(0.324)\end{array}$ & $\begin{array}{c}-0.1937 \\
(0.388)\end{array}$ \\
\hline \multirow[t]{3}{*}{ Observations } & \multicolumn{2}{|c|}{85} \\
\hline & \multicolumn{2}{|c|}{ Placebo 3} \\
\hline & Employment & Productivity \\
\hline Diversification Premium & $\begin{array}{l}0.0947 \\
(0.376) \\
\end{array}$ & $\begin{array}{l}0.4980 \\
(0.464) \\
\end{array}$ \\
\hline Observations & \multicolumn{2}{|c|}{40} \\
\hline
\end{tabular}

Note: Standard errors in parenthesis. The results show estimates of Diversification Premia defined in Equation (22) for each Placebo treatment. The variables used to compute the propensity score are the age of the firm, the squared age of the firm, the FOB value of exports in 2004 and a set of dummy variables for the industry classification at the 4-digit SIC level.

firms. Overall, as in the baseline matching results, the non-linear pattern emerges clearly.

\subsection{Placebo Treatments}

Although we only have cross-sectional information about firms' performance, we have a large Panel with data about firms' access to each foreign market. In this Section, we exploit the rich Panel dimension to construct Placebo treatments which are defined as follows: Firms exporting to a single destination in 2007 and 2008, and which start exporting to 2 destinations in 2009 (Placebo 1), compared to a control group which exports to a single destination in all three years between 2007 to 2009; firms exporting to two destinations in 2007 and 2008, and which start exporting to 3 destinations in 2009 (Placebo 2), compared to a control group which exports to two destinations in all three years between 2007 to 2009; firms exporting to three destinations in 2007 and 2008, and which start exporting to four destinations in 2009 (Placebo 3), to a control group which exports to three destinations in all three years between 2007 to 2009. If the matching of treated and control firms is successful, access to 
Figure 3: Propensity Score Matching
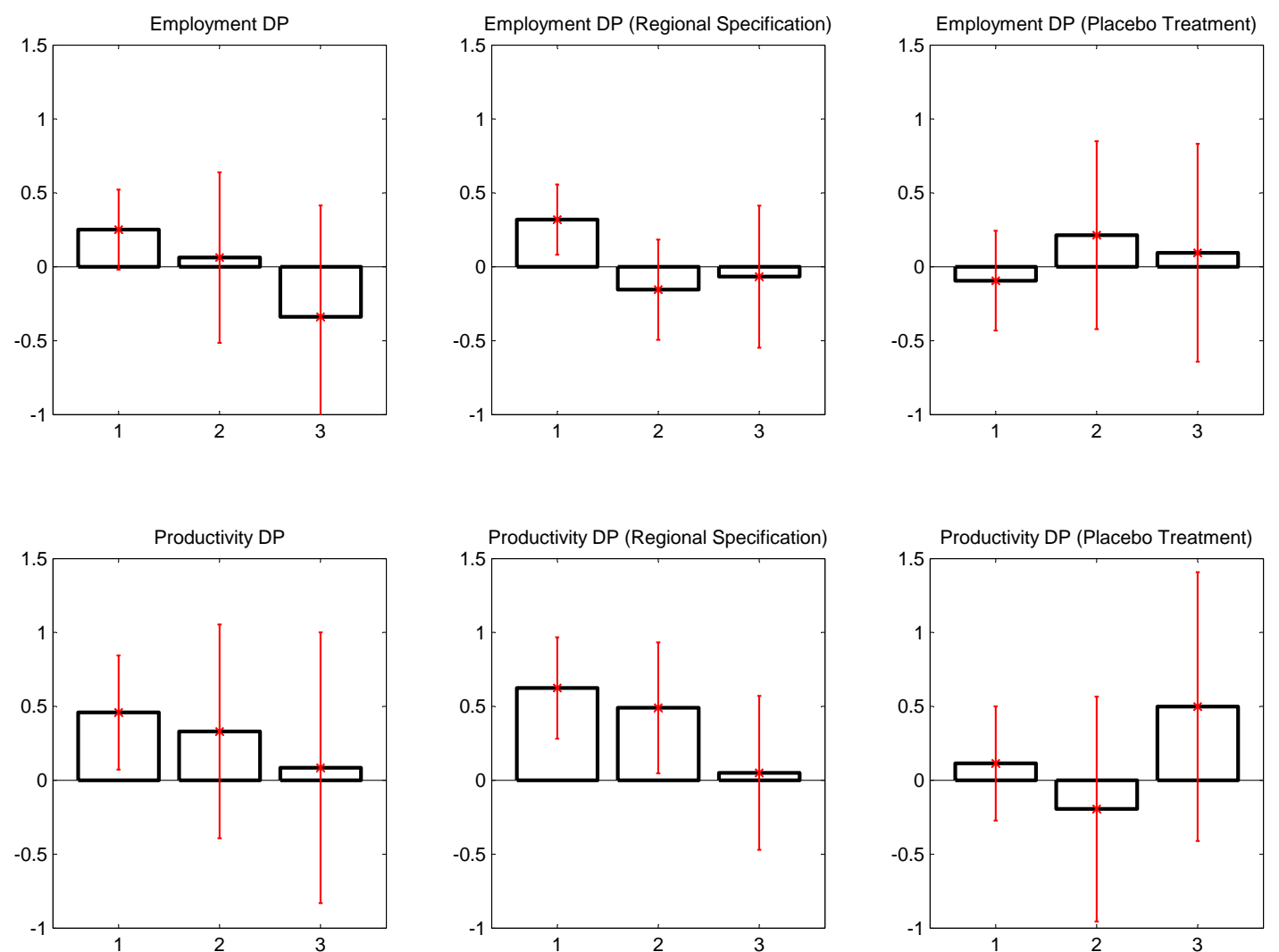

Note: The upper panels are DP for employment and the lower panels are DP for productivity. The left column considers the baseline specification, the middle column the regional specification and the right column the Placebo treatments. In each panel, the bars 1, 2 and 3 correspond to the treatments 1,2 and 3 respectively. The red lines are confidence intervals at the $5 \%$ confidence level.

an additional export market in 2009 should not affect the firm's performance in 2007, our baseline year.

The results are shown in Table 7 and provide a strong validation of the matching approach applied earlier. As predicted, the Placebo treatments are all associated with insignificant treatment effects. The non-linear pattern clearly found earlier does not exist for the Placebo treatments: The treatment effects are no longer large for firms exporting to few destinations initially and small for firms exporting to many destinations. This provides further evidence that the propensity score matching is successful to identify the productivity improvements stemming from diversification.

Figure 3 provides a summary of the findings based on the propensity score matching. The panels on the left column correspond to the baseline specification, the panels on the middle column show the diversification premia for the regional specification. Finally, the left column shows the Placebo treatments. The baseline results are supportive of the of the predictions of 
the model: the diversification premium is large for firms that are initially not well diversified and small for firms already well diversified. The regional specification seems to be a superior measure of diversification because, even for smaller samples, the diversification premia are more precisely estimated. The diversification premia for Treatment 1 and Treatment 2 are larger under the regional specification and the non-linear pattern emerges clearly, in fact we find a non-significant impact on performance in Treatment 3. Finally, the Placebo treatments in the third column validate the propensity score matching since increased access to foreign markets in 2009 does not affect the firm's earlier performance.

\section{Conclusion}

In this paper, we develop and estimate a structural model of technology upgrading by firms that export and face demand uncertainty in their foreign markets. We propose a theory in which exporting to several markets reduces firms' demand uncertainty and, hence, raises the incentives to invest in process innovation, improving its performance. This effect is predicted to be heterogeneous across firms: Serving an additional foreign market contributes more towards lowering uncertainty and raising the incentives to invest for firms that are initially exporting to fewer destinations.

In our model, uncertainty plays a prominent role in shaping firms' investment decisions. Other things being equal, firms with higher perceived uncertainty are less responsive to increases in expected future demand and are less likely to invest in technology adoption. Therefore, export market diversification and not just market size are conducive to process innovation. In our empirical investigation we first examine the relationship between firm's sales volatility and export market diversification. We find strong support for the hypothesis that raising the number of export market destinations reduces demand uncertainty. Starting from a single destination, exporting to an additional destination lowers the volatility of total export sales by roughly $2 \%$.

We estimate the structural model using a large sample of Argentinean manufacturing firms obtained from firm-level customs data. The structural model takes the form of a discrete choice model of technology adoption for which the selection equation depends on observable variables affecting the firm's adoption cost and on a firm specific unobserved component. The structural estimation confirms the hypothesis that an increase in the number of foreign markets raises the threshold maximum adoption cost, implying an increase in the probability that the firm invests in productivity improvements. The firm's age is also found to play an important role: Older firms face lower adoption costs and are therefore more likely to invest in technology upgrades. However, the estimated structural parameters should be interpreted carefully, given the stringent functional form assumptions required. Therefore, we consider several alternative empirical methods, including OLS regressions and a propensity score matching technique. 
When we apply the matching techniques we exploit the fact that our dataset has rich information about the exporting history of the firms. In particular, we match treatment and control groups according to their exporting experience previous to treatment, and other important observable characteristics. We define the treatments narrowly, to identify the heterogeneous effects of improved access to foreign markets across different initial levels of diversification. Consistent with the proposed theory, the diversification premia are decreasing in the number of destinations.

Our results imply that firms that were exporting to a single destination and begin exporting to an additional one become $25 \%$ larger and $46 \%$ more productive in the subsequent year. In the baseline specification, we find no significant diversification effects when we define the treatment group as increasing the number of export destinations from two to three, or three to four. When we define export market destinations in terms of regions instead of countries, the export premia are larger and more precisely estimated, indicating that the regional specification is a superior measure of diversification. The growth in employment and in labor productivity resulting from diversification are estimated at $32 \%$ and $63 \%$, respectively. As a final step, we provide evidence that our matching technique is effective by estimating models that correspond to Placebo specifications. The Placebo treatments have no discernible effect, indicating that our matching techniques are successful. 


\section{References}

Albornoz, F., H. F. Calvo Pardo, G. Corcos, and E. Ornelas (2012): "Sequential exporting," Journal of International Economics, 88(1), 17-31.

Aw, B. Y., M. J. Roberts, And D. Y. Xu (2011): "R\&D Investment, Exporting, and Productivity Dynamics," American Economic Review, 101(4), 1312-44.

Bernard, A. B., And J. B. Jensen (1999): "Exceptional exporter performance: cause, effect, or both?," Journal of International Economics, 47(1), 1-25.

Buch, C. M., J. Dopke, and H. Strotmann (2009): "Does Export Openness Increase Firm-level Output Volatility?," The World Economy, 32(4), 531-551.

Bustos, P. (2011): "Trade Liberalization, Exports, and Technology Upgrading: Evidence on the Impact of MERCOSUR on Argentinian Firms," American Economic Review, 101(1), 304-40.

Chaney, T. (2008): "Distorted Gravity: The Intensive and Extensive Margins of International Trade," American Economic Review, 98(4), 1707-21.

(2011): "The Network Structure of International Trade," NBER Working Papers 16753, National Bureau of Economic Research, Inc.

De Loecker, J. (2007): "Do Exports Generate Higher Productivity? Evidence from Slovenia," Journal of International Economics, 73(1), 69-98.

Doms, M., T. Dunne, and K. R. Troske (1997): "Workers, Wages, and Technology," The Quarterly Journal of Economics, 112(1), 253-90.

Ghironi, F., And M. J. Melitz (2005): "International Trade and Macroeconomic Dynamics with Heterogeneous Firms," The Quarterly Journal of Economics, 120(3), 865-915.

Guiso, L., And G. PARIGi (1999): "Investment And Demand Uncertainty," The Quarterly Journal of Economics, 114(1), 185-227.

Hall, R. E. (1988): "The Relation Between Price and Marginal Cost in U.S. Industry," Journal of Political Economy, 96(5), 921-47.

Hennessy, C. A., And T. M. Whited (2007): "How Costly Is External Financing? Evidence from a Structural Estimation," Journal of Finance, 62(4), 1705-1745.

Hirsch, S., And B. Lev (1971): "Sales Stabilization Through Export Diversification," The Review of Economics and Statistics, 53(3), 270-77.

Koren, M., And S. Tenreyro (2007): "Volatility and Development," The Quarterly Journal of Economics, 122(1), 243-287. 
Lileeva, A., And D. Trefler (2010): "Improved Access to Foreign Markets Raises PlantLevel Productivity... for Some Plants," The Quarterly Journal of Economics, 125(3), 10511099.

Mcguckin, R., M. Streitwieser, and M. Doms (1998): "The Effect Of Technology Use On Productivity Growth," Economics of Innovation and New Technology, 7(1), 1-26.

Melitz, M. J. (2003): "The Impact of Trade on Intra-Industry Reallocations and Aggregate Industry Productivity," Econometrica, 71(6), 1695-1725.

Rosenbaum, P., And D. Rubin (1983): "The Central Role of the Propensity Score in Observational Studies for causal effects," Biometrika, 70(3), 41-50.

(1984): "Reducing Bias in Observational Studies Using Subclassification on the Propensity Score," Journal of the American Statistical Association, 79, 516-524. 


\section{APPENDIX}

\section{A Derivation of the Profit Functions}

If the firm $j$ trades with location $x$, it faces from that location the following isoelastic demand function

$$
p_{j}(x)=\left[e(x) f_{j}(x) / q_{j}(x)\right]^{1 / \sigma}
$$

Two technologies are available, labeled $i=0,1$ and each characterized by a diminishing returns to scale production function of the form

$$
Q_{j}=B_{i} L_{j}^{\alpha}
$$

where $L_{j}$ is the quantity of labor used by firm $j$ to produce total output $Q_{j}=\int_{0}^{n} q_{j}(x) d x$. The profit maximization problem for a firm adopting technology $i$ is

$$
\begin{aligned}
& \pi_{j}^{i}=\arg \max _{q_{j}(x), Q_{j}} \int_{0}^{n}\left[e(x) f_{j}(x)\right]^{1 / \sigma} q_{j}(x)^{1-1 / \sigma} d x-\left(Q_{j} / B_{i}\right)^{1 / \alpha} \\
& \text { st: } Q_{j}=\int_{0}^{n} q_{j}(x) d x .
\end{aligned}
$$

and the first order conditions for optimality are

$$
\begin{gathered}
\rho\left[e(x) f_{j}(x)\right]^{1 / \sigma} q_{j}(x)^{-1 / \sigma}+\lambda=0 \\
-\left(\alpha B_{i}\right)^{-1}\left(Q_{j} / B_{i}\right)^{(1-\alpha) / \alpha}-\lambda=0
\end{gathered}
$$

where $\lambda$ is the Lagrange multiplier, and solving yields

$$
\begin{aligned}
\rho\left[e(x) f_{j}(x)\right]^{1 / \sigma} q_{j}(x)^{-1 / \sigma} & =\left(\alpha B_{i}\right)^{-1}\left(Q_{j} / B_{i}\right)^{\phi} \\
\rightarrow \quad q_{j}(x) & =(\rho \alpha)^{\sigma} B_{i}^{(1+\phi) \sigma} Q_{j}^{-\phi \sigma} e(x) f_{j}(x) \\
\rightarrow \quad Q_{j} & =(\rho \alpha)^{\nu \sigma} B_{i}^{(1+\phi) \nu \sigma}\left[\int_{0}^{n} e(x) f_{j}(x) d x\right]^{\nu}
\end{aligned}
$$

where $\rho=1-1 / \sigma, \phi=(1-\alpha) / \alpha$ and $\nu=1 /(1+\phi \sigma)$. Making use of the optimality conditions (A.4) and (A.5) to substitute in the objective function of problem (A.3) we obtain 
the following profit function for a firm that adopts technology $i$

$$
\pi_{j}^{i}=\kappa\left[B_{i}^{\sigma-1} \int_{0}^{n} e(x) f_{j}(x) d x\right]^{\eta},
$$

with $\eta=\nu / \alpha=[(1-\alpha) \sigma+\alpha]^{-1} \in(0,1)$ and $\kappa=(\alpha \rho)^{(\sigma-1) \nu}(1-\alpha \rho)>0$.

\section{B Proof of Proposition 1}

Consider two firms adopting the same technology and each with the same total mass of customers $m$. From (A.5), the logarithm of the total demand faced by each firm is (up to an additive constant common to each firm) given by

$$
\ln \left(Q_{j}\right)=\nu \ln \left(\int_{0}^{n} e(x) f_{j}(x) . d x\right)
$$

Using the fact that $e(x)=e_{n}$ for all $x \in(n-1, n]$, Equation (B.1) can be expressed as

$$
\ln \left(Q_{j}\right)=\nu \ln \left(\sum_{n \in \Omega_{j}} e_{n} \int_{n-1}^{n} f_{j}(x) d x\right) .
$$

We assume there is no geographic bias in the formation of contact networks: if the firm has contacts in $\bar{n}_{j}$ distinct countries, there is a probability $\bar{n}_{j}^{-1}$ that a contact is located in a given country, and those probabilities are independent across contacts. Thus, for large $m$ the firm will have $m / \bar{n}_{j}$ distinct contacts in each country with whom it trades, which implies that

$$
\int_{n-1}^{n} f_{j}(x) d x=\frac{m}{\bar{n}_{j}} .
$$

Substituting (B.3) in (B.2) yields

$$
\ln \left(Q_{j}\right)=\nu \ln m+\nu \ln \left(\sum_{n \in \Omega_{j}} \frac{e_{n}}{\bar{n}_{j}}\right) .
$$

Since the shocks $e_{n}$ are independently drawn from identical distributions with mean $\mu$ and variance $\sigma_{e}^{2}$, it follows that

$$
\bar{e}_{j}=\sum_{n \in \Omega_{j}} \frac{e_{n}}{\bar{n}_{j}}
$$

is a random variable with mean $\mu$ and variance $\sigma_{e}^{2} / \bar{n}_{j}$. Thus, the variance of the total demand $Q_{j}$ is lower, the higher is the number of export destinations $\bar{n}_{j}$. In other words, the firm that exports to more destinations faces less demand uncertainty. Q.E.D. 


\section{Derivation of the Firm's Adoption Region}

In this Section we show how to derive the adoption region, characterized by the Probit system used in the characterization of the conditional probability of adoption, required to construct the model's Likelihood function.

From Equation (5) in the main text we know that firm $j$ decides to adopt the more efficient technology if

$$
\left(A_{1}-A_{0}\right) \mathbb{E}\left[\left(\sum_{n=1}^{\bar{n}} e_{n} \int_{n-1}^{n} f_{j}(x) d x\right)^{\eta}\right]-C_{j} \geq 0 .
$$

Hence, the maximum cost at which firm $j$ decides to adopt is

$$
C^{\max }=\left(A_{1}-A_{0}\right) \mathbb{E}\left[\left(\sum_{n=1}^{\bar{n}} e_{n} \int_{n-1}^{n} f_{j}(x) d x\right)^{\eta}\right] .
$$

The term inside the expectation operator can be expressed as

$$
\left(\sum_{n=1}^{\bar{n}} e_{n} \int_{n-1}^{n} f_{j}(x) d x\right)^{\eta}=\left(m \sum_{n \in \Omega_{j}} \frac{e_{n}}{\bar{n}_{j}}\right)^{\eta}=m^{\eta} \bar{e}_{j}^{\eta} .
$$

Thus, the log of the threshold value is given by

$$
\ln \left(C^{\max }\right)=\ln \left(A_{1}-A_{0}\right)+\eta \ln m+\ln \mathbb{E}\left[\left(\bar{e}_{j}\right)^{\eta}\right] .
$$

Taking a second order Taylor expansion of $\bar{e}^{\eta}$ around $\mu$ (the mean of $\bar{e}$ ) yields

$$
\bar{e}_{j}^{\eta} \approx \mu^{\eta}+\eta \mu^{\eta-1}(\bar{e}-\mu)+\frac{\eta(\eta-1) \mu^{\eta-2}}{2}(\bar{e}-\mu)^{2}
$$

and, thus, the expectation of $\bar{e}_{j}^{\eta}$ is approximately given by

$$
\begin{aligned}
\mathbb{E}\left[\left(\bar{e}_{j}\right)^{\eta}\right] & =\mu^{\eta}+\frac{\eta(\eta-1) \mu^{\eta-2}}{2} \mathbb{E}\left[(\bar{e}-\mu)^{2}\right] \\
& =\mu^{\eta}+\frac{\eta(\eta-1) \mu^{\eta-2}}{2} \frac{\sigma_{e}^{2}}{\bar{n}_{j}} \\
& =\mu^{\eta}\left(1+\frac{\eta(\eta-1) \mu^{\eta-1}}{2} \frac{\sigma_{e}^{2}}{\bar{n}_{j}}\right) .
\end{aligned}
$$


It follows that $\ln \mathbb{E}\left[\left(\bar{e}_{j}\right)^{\eta}\right]$ can be expressed as

$$
\begin{aligned}
\ln \mathbb{E}\left[\left(\bar{e}_{j}\right)^{\eta}\right] & =\eta \ln \mu+\ln \left(1+\frac{\eta(\eta-1) \mu^{\eta-1}}{2} \frac{\sigma_{e}^{2}}{\bar{n}_{j}}\right) \\
& \approx \eta \ln \mu+\frac{\eta(\eta-1) \mu^{\eta-1}}{2} \frac{\sigma_{e}^{2}}{\bar{n}_{j}}
\end{aligned}
$$

where the approximation made in the final step assumes $\mu^{\eta-1} \sigma_{e}^{2}$ to be a small number. Finally, using (C.4) to substitute in (C.3) yields

$$
\ln \left(C^{\max }\right)=\ln \left(A_{1}-A_{0}\right)+\eta \ln m+\eta \ln \mu+\frac{\eta(\eta-1) \mu^{\eta-1}}{2} \frac{\sigma_{e}^{2}}{\bar{n}_{j}} .
$$

The variable $\bar{n}_{j}$ corresponds to the number of export markets served by firm $j$ and we have an exact empirical counterpart that we label $(\text { DEST })_{j}$. The variable $m$ corresponds to the total number of customers served by the firm $j$. We do not observe this variable directly but we observe the total value of exports by firm $j$, labeled $(\mathrm{FOB})_{j}$. Notice that, given the assumed CES demand system, the total sales are proportional to the number of clients. Therefore, we use $(\mathrm{FOB})_{j}$ as a proxy for $m$. We rewrite (C.5) as follows

$$
\ln \left(C^{\max }\right)=\phi_{0}+\phi_{1} \ln (\mathrm{FOB})_{j}+\phi_{2}\left(\frac{1}{\mathrm{DEST}}\right)_{j}
$$

with

$$
\begin{aligned}
& \phi_{0}=\ln \left(A_{1}-A_{0}\right)+\eta \ln \mu>0, \quad \phi_{1}=\eta>0 \quad \text { and } \\
& \phi_{2}=\frac{\eta(\eta-1) \mu^{\eta-1}}{2}<0 .
\end{aligned}
$$

Equation (C.6) corresponds to Equation (11) in the main text.

Finally, we need to assume a conditional distribution for the firm's adoption cost. We assume that the log of the adoption cost is a function of observable characteristics including the age of the firm (AGE) in logs, and the annual value of export shipments (FOB) also in logs, plus a random component

$$
\ln (C)_{j}=\alpha_{0}+\alpha_{1} \ln (\mathrm{AGE})_{j}+\alpha_{2} \ln (\mathrm{FOB})_{j}+\varepsilon_{j},
$$

where $\varepsilon_{j} \sim N(0,1)$. The above equation corresponds to Equation (10) in the main text.

Of course, the firm adopts the more efficient technology if the cost of adopting does not 
exceed the threshold. In other words, the firm adopts if

$$
\begin{aligned}
Z_{j} & =\ln (C)_{j}-\ln \left(C^{\max }\right)_{j} \\
& =\left(\alpha_{0}-\phi_{0}\right)+\alpha_{1} \ln (\mathrm{AGE})_{j}+\left(\alpha_{2}-\phi_{1}\right) \ln (\mathrm{FOB})_{j}-\phi_{2}\left(\frac{1}{\text { DEST }}\right)_{j}+\varepsilon_{j} \leq 0 .
\end{aligned}
$$

and, hence, the adoption region is characterized by the selection model implied by the equations (12) and (13).

\section{Proof of Proposition 2}

The maximum cost at which firm $j$ decides to adopt is given by (C.2), and can be reexpressed as

$$
C^{\max }=\left(A_{1}-A_{0}\right) m^{\eta} \mathbb{E}\left[\left(\bar{e}_{j}\right)^{\eta}\right]
$$

where

$$
\bar{e}_{j}=\sum_{n \in \Omega_{j}} \frac{e_{n}}{\bar{n}_{j}},
$$

is a random variable with mean $\mu$ and variance $\sigma_{e}^{2} / \bar{n}_{j}$, and $\eta=[(1-\alpha) \sigma+\alpha]^{-1}$ is a positive parameter less than one. Therefore, $\left(\bar{e}_{j}\right)^{\eta}$ is concave in $\bar{e}_{j}$ and it follows from Jensen's inequality that $\mathbb{E}\left[\left(\bar{e}_{j}\right)^{\eta}\right]$ is decreasing in the variance of the random variable $\bar{e}_{j}$. Since an increase in the number of foreign markets served, $\bar{n}_{j}$, lowers the variance of $\bar{e}_{j}$, it follows that, given two firms with the same total mass of customers $m$ (assumed to be large in the sense that each firm has $m_{j} / \bar{n}_{j}$ customers in each foreign market that it serves) the maximum adoption $\operatorname{cost} C^{\max }$ at which the firm chooses to adopt the better technology is higher for the firm that exports to more destinations. Q.E.D. 